\title{
ÇAĞATAY TÜRKÇESİNDEKİ GÖLGE KELIMMELERDEN BİRİ: ÜRKÜN
}

Sinan UYĞUR*

\author{
$\ddot{O} z$
}

Çağatay Türkçesi, Türk dili tarihinde sözlükçülük alanında önemli bir yere sahiptir. Başlarda Çağatay, Osmanlı, İran ve Hindistan sahalarında oluşturulan Çağatayca ile ilgili sözlükler daha sonra Avrupa'da da tercüme ve telif edilmeye başlanmıştır. İlk sözlüklerde meydana gelen yanlışlar dönemin imkânsızlıkları sebebiyle daha sonrakiler tarafindan tashih edilemeyerek nakledilmiştir. Bu makalede de bir noktalama yanlışından doğan "ürkün" kelimesinin macerası ele alınmıştır.

Anahtar Sözcükler: Çağatayca, Çağatayca sözlükler, gölge kelime, ürkün, üzgün.

\section{ONE OF THE GHOST WORDS IN CHAGATAI LANGUAGE IS: URKUN}

\begin{abstract}
Chagatai Turkic Language has an important place in the field of lexicography in the history of Turkish language. Chagatai dictionaries initially compiled in Chagatai, Ottoman, Persian and Indian regions subsequently began to be translated and complied in Europe too. Errors occurring in the first dictionaries were conveyed without being corrected by the later ones due to the impossibilities of the period. This article addresses the adventure of the word "ürkün" which emerged from a punctuation error.
\end{abstract}

Keywords: Chagatai Turkic language, Chagatai dictionary, ghost word, urkun, uzgun.

Gölge kelime (ghost word), gerçekte var olmayan; ancak sözlük müelliflerinin şu veya bu şekilde kayda geçirdikleri ve pekçoğu da tashih edilmeden günümüze ulaşabilmiş kelimeleri karşılayan bir kavramdır (Hartmann ve Gregory, 1998, s. 63; Dankoff, 2008, s. 12; Erbay, 2010, s. 1176). Türk dilinin kadim bir dil olması ve tabiatıyla pek çok sözlügünün bulunması bir kısım sapmaları da beraberinde getirmiştir. Bu sapmaların büyük bir kısmının aktarmada meydana geldiği ve bunda aktarıcıların büyük rol oynadıkları bu alanda yapılan çalışmalardan anlaşılmaktadır.

Türk dilindeki sözlerin bir Türk tarafından kayda geçirilmiş ilk sözlüğü, Divânu Lugâti't-Türk'tür. Sözlüğün Kaşgarlı Mahmud'un zihin süzgecinden süzülerek yazıya geçen sözlerden oluşması, eserdeki söz varlığının olabildiğince doğru olduğu kanaatini hâsıl etmekteyse de bunun böyle olmadığı "chatuq" kelimesinin "khutū” okunması gerektiğini ortaya koyan Dankoff'un (1973, s. 542-543) çalışmasından sonra daha iyi anlaşılmıştır. Ancak

\footnotetext{
* Yrd. Doç. Dr.; Artvin Çoruh Üniversitesi Fen Edebiyat Fakültesi Türk Dili ve Edebiyat1 Bölümü, turkoloji@yahoo.com.
} 
bahsedilen kelimenin bu tashihten sonra yapılan yayınlarda bile varlığını devam ettirdiği görülmektedir (Ercilasun ve Akkoyunlu, 2014, s. 617; Üşenmez, 2006, s. 181). Aynı dönemde yazılmış Satıraltı Kuran Tercümesinin Rylands Nüshasının söz varlığını ortaya koymak için Eckmann'ın yazdığı eseri (1976) üzerine Bodrogligeti tarafindan yapılan inceleme (1984) de bir dönemin söz varlığını ortaya koymanın ne denli zor olduğunu göstermesi açısından önemli bir çalışmadır.

Türk dili tarihinde, özellikle sözlükçülük açısından Çağatay Türkçesinin önemli bir yeri vardır. 14. yüzyılın son çeyreğinden 20. yüzyılın ilk çeyreğine kadar Türk yazı dilinin doğu kolunu oluşturan Çağatay Türkçesi ile 550 yıla baliğ bir süre zarfında büyük bir edebiyat oluşturulmuş ve bu edebiyat geniş coğrafyalarda okuyucu bulmuştur. Özellikle Ali Şir Nevâŷ̂’nin vücuda getirdiği eserler mekân ve zaman aşırılık nitelikleriyle takip ve taklit edilmiştir. Nevâyî’nin dilini anlamak içinse pek çok sözlük hazırlanmıştır. Bir kısmı Lügat-i Nevâyî olarak da adlandırılan bu sözlüklerde hazırlayıcılarının veya eserleri çoğaltanların ihmalkârlıkları, bilgisizlikleri veya düzeltmeleri yapabilecek iletişim ve ulaşım araçlarından yoksun oluşları hata yapmalarına veya bu hataları çoğaltıp yaymalarına sebep olmuştur. Bir kısmı birbirinden habersiz hazırlanan bu sözlüklerden özellikle biri vardır ki onun müellifini bu sahada ilk gölge kelime tespitçisi olarak görmekteyiz. "Senglax" isminde dilbilgisi ve sözlük kaleme alan Mirza Mehdi Han-1 Esterabadî devrinin imkânları ölçüsünde Çağatay Türkçesinin çeşitli metinlerinden ve kendinden önce yazılmış lügatlerden istifade edip bunları mukayese etmiş, bu sözlüklerdeki bazı maddelerde de düzeltme yapmıştır (Clauson, 1960). Mehdi Han, Çağatayca sözlükler sahasında bir çı̆̆ır açmış, kendinden sonra birçok sözlükçü tarafından da örnek alınmıștır.

Batıda ise Macar ālim József Thúry, Feth Ali Kaçar'ın Behçetü'l-Lugat adlı eseri üzerine yazdığı BL'de (1903), Çağataycada var olduğu düşünülen "ašukluk zilki”, “almajaš”, "uratlašmak", "tükek”, "bidkan” ve "bilnek” gibi pek çok gölge kelime tespit etmiştir. Bu eserin üzerinden uzun yıllar geçtikten sonra bizde Hasan Eren, Çağatayca sözlükler üzerine yazdı ̆̆ makalesinde (1950, s. 145-163) Thúry'nin çalışması üzerinde durduktan sonra "debr”, "isir”, “onzel”, "şişal”, "ḳumşum” gibi bazı Çağatayca gölge kelimeler üzerinde durarak düzeltme önerilerinde bulunmuştur. Clauson ise "Sanglax" adlı yayınının giriş bölümünde çeşitli kelimelerin Çağatay Türkçesi ile ilgili yazılan sözlüklerde nasıl değişebildiğini göstererek bir değerlendirme yapmıştır (Clauson, 1960, s. 3-32). Fatih Erbay, Radloff'un "Versucheines 
Wörterbuches der Turk-Dialecte" üzerine hazırladı̆̆ 1 doktora tezinde (2008), eserdeki Çağatayca ibareli kelimeleri kritik ederek sözlük müellifinin bir kısım hatalar yaptı̆̆ını göstermiştir. Ayrıca ‘Gölge Kelime’ Terimi ve Çağatayca Sözlüklerdeki Bazı Gölge Kelimeler” isimli makalesinde (2010) "ahsadurġa”, "arḳaġlaça”, "aşḳış", “aşlar”, "bilekçi”, “çens”, debrdabır-dabir”, “ebegü”, “isir”, "ḳaruḳ”, “mamur”, “sayġur”, “söksüll”, “toşuk-tuşuk”, “tut”, “yile", "yı̇gak-yiganĝ" ve "yümrek ḳazıg’" kelimeleri üzerine durup durum tespiti yaptıktan sonra bir kısmı için de düzeltme önerisinde bulunmuştur. Niyâzi'nin müellifi veya müstensihi olduğu Ellug̉atu'n-Nevā'iyye ve'l-istişhādātu'l-Cag̀ātā'iyye isimli eseri üzerine hazırladığı çalışmasında Mustafa S. KAÇALİN, bu sözlükteki hataları "karışmış maddeler", "mükerrer maddeler", "tutarsız bilgilendirmeler", "yanlış açıklamalar", "yanlış alıntılar", "yanlış ayırmalar", "yanlış göndermeler", "yanlış harflendirmeler", "yanlış karşllıklar", "yanlış maddeler", "yanlış noktalamalar", "yanlış okumalar" ve "yanlış örneklemeler" sınıflandırmasıyla değerlendirmiştir (Kaçalin, 2011, s. 33-34). KAÇALİN'in titiz çalışması sayesinde Abuşka Lugati olarak maruf eserdeki pek çok hata tekrardan kurtulmuştur.

Yukarıda bahsedilenlerden anlaşılacağı üzere, Çağatayca sözlüklerde pek çok hata mevcuttur. Bu hataların oluşmasında ve bugüne ulaşmasında Çağatayca sözlüklerin mekân ve zaman aşırı oluşturulmuş olmaları, sözlüklere kaynaklık eden malzemenin kalitesizliği gibi bir kısım sebebin varlığından söz edilebilir. Ancak bugün geçmişten farklı olarak iletişim ve ulaşım alanında yaşanan gelişmelerle bilgiye ulaşmada kısmî kolaylaşma, geçmişteki imkânsızlıklar sebebiyle ortaya çıkan hataların tashihini mümkün kılmaktadır. Bu alanda yapılan çalışmaların bir araya getirilebilecek duruma gelinmesi elbette bilimin bir bölümü olan mukayeseyi de kolaylaştırmıştır. Ancak hâlen bir kısım sıkıntı varlığını devam ettirmektedir. Burada vazifenin büyüğü, millet namına bilgi toplama ve bilgiye ulaşımı kolaylaştırma işiyle meşgul olanlara düşmektedir. Bilgiyi üretmenin ilk aşaması olan üretilmiş bilgilere erişmede karşılaşılan zorluklar bugün dahi bilim insanlarının önünde büyük bir engel teşkil etmektedir. Bilgiyi ulaşılabilir kılmanın bilim üretimine ivme kazandıracağı da muhakkaktır. Çağatayca üzerine yapılacak çalışmaların daha sağlıklı olabilmesi de eldeki mevcut bütün malumatın herkesin -en azından ilgili insanların- ulaşabileceği bir sistem dâhilinde olmasına bağlıdır.

Bu makalede de Çağatay Türkçesi üzerine hazırlanmış sözlüklerde 500 yıla yakın bir süre varlığını sürdürmüş, hatta sözlüklerden çıkıp aslının yerine geçmeye muvaffak olabilmiş “ürkün / kelimesi ele alınacaktır. Kelimenin Çağatay Türkçesinde var olduğunu ilk öne 
süren sözlük Abuşka Lugati'dir. Bu sözlük kendinden sonraki bazı sözlüklere de kaynak teşkil etmiş, bir hayli istinsah edilmiş ve 150 yıla yakın bir süredir de Doğuda ve Batıda üzerinde çalışılarak yayınlanmıştır. Eser üzerine yapılan çalışmalara bakıldığında Ármin Vámbéry,

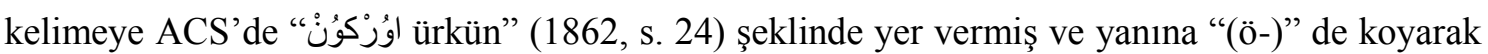
“örkün” okunabileceği ihtimalini göz önünde bulundurmuştur. Véliaminof-Zernof, DDT'de kelimeyi "وركون" (1869,s. 101) şeklinde aslına uygun olarak vermiştir. Eserin Türkiye'deki ilk yayını olan AL'de ATALAY, kelimeyi "ürkün” (1970, s. 97) olarak okumuştur. Abuşka Lugati'nin Ayasofya, Esad Efendi, Lala İsmail, Seyfettin Özege, Şehid Ali Paşa nüshaları ve Besim ATALAY'ın çalışmasından yararlanarak Muharrem GÜZELDİR bir doktora çalışması yapmış, sonuçta on kadar nüshanın karşılaştırılmasıyla en kapsamlı Abuşka Lugati ortaya ç1kmıştır. GÜZELDİR'in oluşturduğu karşılaştırmalı metinde kelime "ürkün, (اوركون)" (2002, s. 138) şeklinde yer almaktadır. Ayrıca GÜZELDİR düştüğü dipnotta "Bu madde S. [Seyfettin Özege] nüshasında yoktur. $\mathrm{Bu}$ maddedeki açıklamaları ve tanı̆̆ı "örtük" kelimesinin açıklamasında vermiştir" (2002, s. 138) bilgilerini araştırmacıların dikkatine sunmaktadır. Bu eserin Esad Efendi Nüshası üzerine Mustafa S. KAÇALİN ayrıntılı bir çalışma yapmıştır. KAÇALİN, eser üzerine daha önce yapılan çalışmalarla Çağatayca ile ilgili yayınlanmış sözlüklerin ve örneklendirilen maddelerin örneklerinin geçtiği eserlerin ilgili yerlerinden hareketle bir metin kurma yoluna gitmiştir. Bu çalışmada da kelime "ürkün” (Kaçalin, 2011, s. 273) olarak değerlendirilmiştir.

Abuşka Lugati'ni kaynak olarak kullandığı anlaşılan Budagov, LT’de kelimeyi "ورُرْكونْ" olarak kaydetmiş ve kelimenin ilk ünlüsünün "ü” olduğunu göstermek üzere ayraç içinde “(ÿ)" imi koymuştur (1869, s. 125). Zenker de DTAP'deki Çağatayca kelimeleri Abuşka Lugati'nden derlemiş ve kelimeye eserinde "وُوكؤن" (1888, s. 117) şeklinde yer vermiştir. Bahsedilen kaynaklardan DTAP hariç diğerlerinde Ali Şir Nevâyî'nin Nevâdirü'ş-Şebâb'ındaki “Derd kör kim istese kilmek gamın sormaḳka yār / Rāżì irmen kim sirişkim seylining bar ürküni”" (Karaörs, 2006, s. 588) mısraları kelimeye tanık olarak gösterilmiştir. Zenker ise kelimenin Ferhad ü Şirin'de yer aldığını belirtse de yapılan taramada böyle bir kelimenin bu eserde geçmediği tespit edilmiştir. Yani kelime tek bir yerde kullanılmış ve sadece bu kaynakta ve bu kaynaktan beslenmiş yukarıda ismi geçen sözlüklerde yer almıştır. $\mathrm{Bu}$ durumun olma ihtimalinin çok küçük olduğu düşünülerek daha etraflı bir tarama yapılmış, bir kısım sözlükte kelimenin aynı karşıllk ve örnek ile "üzgün” şeklinde geçtiği belirlenmiştir. 
“Üzgün - اوزكون" kelimesinin ilk geçtiği sözlük Mirza Mehdi Han'ın Senglax adlı (Clauson, 1960, s. 39, 74r; Xiyavi, 1374, s. 46) eseridir. Senglax'a dayanılarak hazırlanan Hulasa-i Abbasi'de ise kelime "اوزكون üzkün” (Düzgün, 1388, s. 133) şeklindedir. Kelime Nevâyî’nin eserleri üzerine Özbekistan'da hazırlanmış üç sözlükte de “узгун” (Şamsiyev ve İbråḩimov, 1972, s. 622; Kononov vd., 1984, s. 277; Xasanov, 1993, s. 285) şeklinde verilmiştir.

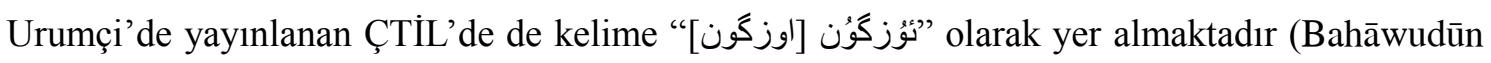
vd., 2002, s. 736). Bu sözlüklerin tanık gösterenlerinin kelimeyi yine Ali Şir Nevâyî’nin aynı beytiyle örneklendirmeleri (Clauson, 1960, s. 74r; Şamsiyev ve İbråhimov, 1972, s. 622; Kononov vd., 1984, s. 277; Bahāwudūn vd., 2002, s.736) kelimenin Çağatay Türkçesinde başka bir yerde kullanılmadığı izlenimi oluşturmaktadır. Nevâyî’nin yayınlanmış eserleri tarandığında başka bir yerde tespit edilemeyen kelimeye, Hüseyin Baykara Divanı'nda "seyl-i eşkim yir yüzin tuttı sayang irken zamān / yoḳ ‘aceb gerdūnnı ḳılsa ġarḳa anıng üzgüni” (Yıldırım, 2002, s. 176) beytinde rast gelinmiştir. Yani kelime tek bir yerde karşımıza çıkan, başka bir yerde örneğine rastlanmayan kelimelerden (hapax legomenon) değildir.

İşin asıl ilginci bazı sözlüklerde de kelime hem “ürkün” hem de "üzgün” biçiminde yer almaktadır. Fransız âlim Pavet de COURTEILLLE'in hazırladığı PdC'de kelime yine "وروكون" (1870, s. 57) ve "(1870, s. 63) biçiminde bulunmaktadır. "Ürkün” kelimesi Şeyh Süleyman Efendi'nin eserinde de "اوركون" (1298, s. 30) ve "اوزكون" (1298, s. 33) olarak iki şekilde kaydedilmiştir. Süleyman Efendi’nin eserini Avrupa'da yayınlayan Kúnos'un eserinde ise kelime, "ürkün” (1902, s. 160) ve "özgün” (1902, s. 156) şeklindedir. Radloff da VE'de kelimeyi “ӱргён [اوركون]” (1893, s. 1840) ve “ӱзгён [اوزكون]” (1893, s. 1901) olmak üzere ayn1 anlamla iki ayrı yerde kaydetmiştir. Aynı eserde "(Osm.)” ibaresiyle aynı anlamda bir “ӱркӱн [اوركون]" (Radloff, 1893, s. 1837) kelimesi daha bulunmaktadır ki Osmanlı Türkçesinde bu manada böyle bir kelime tanıtlanmış değildir. Suat ÜNLÜ’nün Çağatay Türkçesi Sözlüğü’nde ise kelime “örkün” (2014, s. 877), “özgün” (2014, s. 883), “ürkün” (2014, s. 1199), “üzgün” (2014, s. 877) olmak üzere dört farklı şekilde yer almaktadır.

Kelimeye Behçetü'l-Lugat’te (Thúry, 1903), Bedāyiu'l-Lugat'te (Borovkov, 1961), Der Beyân-1 Istılâhât-1 Emtahü'ş-şu'arā Mevlânâ Nevâyî'de (Özkan, 1996), TschaghataischDeutsches Glossar'da (Prokosch, 2009), Zebân-1 Türkî'de (Kara, 2011) ve Nisâb-1 Türkî'de (Sarıca, 2014) ise yer verilmemiştir. Elbette bu yer verilmeyişin sebebi olarak kelimenin yok denecek geçiş sıklığını göz önünde bulundurmak gerekir. 
Kelimedeki çeşitlenmeyi ilk tespit eden, Mirza Mehdi Han olmuştur. Abuşka Lugati müellifinin yanıldığını ifade eden Mehdi Han (Clauson, 1962, s. 74r) böylece bir gölge kelimeyi ortadan kaldırdığını düşünmüş olsa da yukarıda görüldüğü üzere kelime bugüne kadar nakledilegelmiştir. Hatta sözlük sahifelerinden çıkıp Ali Şir Nevâyî’nin Nevâdirü'ş-Şebâb'ında gerçeklik dünyasına adımını atmıştır (Karaörs, 2006, s. 588).

Hakikaten Mirza Mehdi Han'ın düşündüğü gibi Abuşka Lugati müellifi veya müstensihi mi var olmayan bir kelimenin ortaya çıkmasına sebebiyet vermiştir? Bu kelimede eserin nüshaları arasındaki tutarlılık, müstensihleri kurtarmakta, bu hususta dikkatleri müellifin üzerine odaklamaktadır. Her ne kadar Abuşka müellifinin, iki kelimenin yazılışı arasındaki farkın sadece bir noktadan ibaret olması, kelimenin geçiş sıklığının düşük olması gibi sebeplerle hata yapmış olduğu ilk bakışta akla gelmekteyse de hatayı ondan daha önce bir müstensihin yapmış olabileceği düşünülerek Nevâŷ̂’nin ilgili eserinin nüshaları tedarik edilmeye çalışılmış ve elde edilenler üzerine yapılan bir incelemede Mirza Mehdi Han'1 değil de Nevayi’nin aşağıda alıntılanmış olan Mahbûbu'l-Kulûb'undaki sözlerini doğrulayıcı bir sonuca ulaşılmıştır. Bu amaçla eserin Topkapı Sarayı Müzesi Kütüphanesinde TSMK Revan ktp. 805, 807 ve 808 nolu, Süleymaniye Kütüphanesi'nde Fatih ktp. 3886, Fatih ktp. 4056 nolu, BibliothèqueNationale de France'da Supplement Turc 317 nolu, İstanbul Üniversitesi Kütüphane ve Dokümantasyon Daire Başkanlığı Nadir Eserler Kütüphanesi T2001 nolu yazmaları taranmış, yapılan mukayesede bunlardan Fatih ktp. 3886 nolu yazmada ilgili kelimede "ze"nin noktasının konmadığı tespit edilmiştir. Fatih ktp. 3886 nolu nüshanın müstensihinin, istinsah edildiği yerin ve istinsah tarihinin belli olmaması kesin bir sonuca varılmasını engellemektedir. Kelimenin Nevâdirü'ş-Şebâb'ın Özbekistan'daki yayınında “ўз куни” olarak yer alması (Mutallibov, 1989, s. 428) da eserin hatalı nüshasının sadece bizde olduğunu göstermektedir. Buna göre Abuşka müellifi eserin ya bu nüshasından veya bu nüshaya kaynaklık etmiş ya da bu nüshadan çoğaltılmış başka bir nüshasından istifade etmiş olmalıdır. Nüshanın İstanbul'da bulunuyor olması da bu fikri desteklemektedir.

Müelliflerin yazdıklarını istinsah ederek geçimlerini sağlayan müstensihlerin işinin pek çok zorluğunun olduğu ortadadır. Kaynak metinden hedef metin oluşturma işi olarak tanımlanabilecek işlerinde kaynak metnin niteliksizliği hedef metnin bozulmasına sebep olduğu gibi aktarıcının niteliği de bu işin kalitesini belirleyici bir unsurdur. Bunun için birçok müellif, müstensihlerin eserlerini bozduklarından yakınmıştır. Fuzuli'nin bu konuda yakınması meşhursa 
da Çağatay edebiyatının çınarı Ali Şir Nevâyî de Mahbûbu'l-Kulûb'da (Ölmez, 1993, s. 116118) kâtiplerden şöyle yakınmaktadır:

Hōşnūvis hem kim sehvi köp bolg̀ay ilgi felc 'illeti-ġa cöb bolgay. Ol-ki bí-cānoḳta

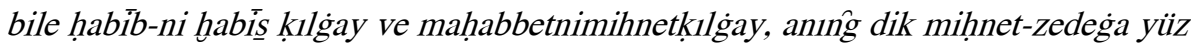
la'net. Yaman hat-ka galat-ı bỉ-hisāb, karı masharasakalı-ğa hiżāb. Ol sakal mebrezġa taşlag̉alı yahşsı ve ayasınımālik-i dūzah̆ cehennem-ġa başlag̉alı yahşsı.

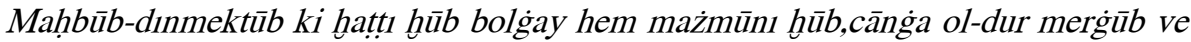
köngülge ol-dur mațlūb. Hatț yaman hem bolsa yaman imesmuhibbmạ̣būb hatținı yaman dimes. Yaman kātibmenzili ḳalem-dānı dik çāh ara bolsun, kalemi dik başı yara ve yüzi kara bolsun.

Beyt,

Kaysı bir kātib ki ol sözge kalemsürgey hilāf

Ol ḳara yüzlük başı bolsun ḳalem yanghglıg şikāf"

Nevâyî'nin bu ifadeleri aksülamel bulmamış olacak ki onun eserlerinde de müstensihlerin marifetiyle pek çok nüsha farklılı̆ğ oluşturulmuş ve tarihî süreçte bunlar aktarılagelmiştir. Üstelik yapılan yanlışlar da gerçekmiş gibi kabul edilerek bunların üzerine bilgi inşa edilmiştir. Etkisi, eserleri üzerine sözlükler telif edilecek kadar büyük olan Nevâyî'nin eserlerindeki bozulmanın bu sözlüklerde gölge kelime türeyişine sebebiyet verdiğini burada ele alınan "ürkün” kelimesinin macerası ortaya koymaktadır. Bugün eldeki imkânların geçmişten fazla olması, bu hataların bir kısmının tashih edilmesini sağlasa da henüz Türkiyat veri tabanının meydana getirilememesi böyle kelimelerin bir zaman daha varlığını devam ettireceğini göstermektedir.

\section{Eser Kısaltmaları}

ACS: Abuska Csagatajtörök Szogyüjtemeny
AL: Abuşka Lûgatı veya Çağatay Sözlüğü
BL: A 'Behdset-ül-Lugat' Czimü Csagatáj Szótár
ÇTíL: Çağatay Tiliniñ İzāhliḳ Luğati
DDT: Dictionnaire Djaghataï-Turc 
LT: Sravnitelnıy Slovar Turetsko-Tatarskih Nareçiy

NS: Nevāyī'nin Sözleri ve Çağatayca Tanıklar

PdC: DictionaireTurcOriental

DTAP: Dictionnaire Turc-Arabe-Persan

VE: VersuchEinesWörterbuchesderTürk-Dialecte I-IV

\section{Kaynaklar}

Ali Şir Nevâyî (Yazma). Divan-ı Nevai. Topkapı Sarayı Müzesi Kütüphanesi Revan ktb. 805.

Ali Şir Nevâyî (Yazma). Divan-ı Nevai. Topkapı Sarayı Müzesi Kütüphanesi Revan ktb. 807.

Ali Şir Nevâyî (Yazma). Külliyat-ı divan-ı Nevai. İstanbul Üniversitesi Kütüphane ve Dokümantasyon Daire Başkanlığı Nadir Eserler Kütüphanesi T2001.

Ali Şir Nevâyî (Yazma). Külliyât-ı Nevai. Topkapı Sarayı Müzesi Kütüphanesi Revan ktb. 808.

Ali Şir Nevâyî (Yazma). Külliyât-ı Nevâyî. BibliathèqueNationale de France, Supplement 317.

Ali Şir Nevâyî (Yazma). Nevayi külliyatı. Süleymaniye Yazma Eser Kütüphanesi Fatih ktb. 3886.

Ali Şir Nevâyî (Yazma). Nevayi külliyâtı. Süleymaniye Yazma Eser Kütüphanesi Fatih ktb. 4056.

Bahāwudūn, M. vd. (2002). Çăgatay tiliniñ izāhlik luġati cilt 1-II. Urumçi: Şincañ Halk Neşriyātı.

Bodrogligeti, A. (1984). "Ghosts, copulating friendsand pedestrian locusts in sone reviews of eckmann's 'middle turkic glosses"”. Journal of the American Oriental Society, Vol. 104, No. 3, 455-463.

Borovkov, A. K. (1961). Bada'i al lugat. Moskva: Akademiya Nauk SSSR.

Budagov, L. Z. (1869). Sravnitelnıy slovar Turetsko-Tatarskih Nareçiy I. Cilt. Saint Petersburg: Tipografiya Imperatorskoy Akademiy Nauk.

Clauson, G. (1960). Sanglax, A Persian Guide to theTurkish Languageby Muhammad Mahdi Xan. London: E. J. W. Gibb Memorial Series.

Courteille P. De (1870). DictionaireTurc oriental. Paris: A L“imprimerie Impériale.

Dankoff, R. (1973). "A Note on khutū and chatuq". Journal of the American Oriental Society, Vol. 93, No. 4, 542-543. 
Dankoff, R. (2008). Evliya Çelebi seyahatnamesi okuma sözlügü̈. (çev. Semih TEZCAN), İstanbul: Yapı Kredi Yayınları.

Düzgün, H. (1388). Həkim Məhəmmad Hoyi Xulase-yi Ebbasi (Sənglax). Tebriz: İntişarat-1 Azerbaycan.

Eckmann, J. ( 1976). Turkic glosses of the rylands interlinear koran translation. Budapest: Akadémiai Kiadó.

Erbay, F. (2008). W. Radloff" un "Opıt Slovarya Tyurkskih Nareçiy" Adlı Eseri ve Eserde Geçen Çağatay Türkçesine Ait Kelimelerin İncelenmesi. Yayımlanmamış doktora tezi, Konya: Selçuk Üniversitesi Sosyal Bilimler Enstitüsü.

Erbay, F. (2010). "Gölge kelime" terimi ve Çağatayca Sözlüklerdeki Bazı Gölge Kelimeler”.Turkish Studies, Volume 5/3 Summer 2010, 1175-1186.

Ercilasun, A. B. ve Akkoyunlu, Z. (2014). Kâşgarlı Mahmud dîvânu lugâti 't-türk giriş-MetinÇeviri-Notlar-Dizin. Ankara: Türk Dil Kurumu Yayınları.

Eren, H. (1950). Çağatay Lûgatleri Hakkında Notlar. (Cilt 8). A.Ü.D.T.C.F. Dergisi, 1. 2, 145 163.

Güzeldir, M. (2002). Abuşḳa Lügati (Giriş-Metin-İndeks). Yayınlanmamış doktora tezi, Erzurum: Atatürk Üniversitesi Sosyal Bilimler Enstitüsü.

Hartmann, R. ve Gregory, J. (1998). Dictionary of lexicography. London-NewYork: Routledge.

Kaçalin, M. S. (2011). Nevāyī’nin sözleri ve Çağatayca Tanıklar. Ankara: Türk Dil Kurumu Yayınları.

Kara, F. (2011). Zebân-ı Türkî. Erzurum: Fenomen Yayınları.

Karaörs, M. (2006). ‘Alì Şir Nevāyī Nevādirü’ş-şebāb. Ankara: Türk Dil Kurumu Yayınları.

Kononov, A. N. vd. (1984). Alişer Navåiy asarlari tilining izåxli luğati III. Cilt. Tåşkent: O’zbekistån SSR “Fan” Naşriyåti.

Kúnos, I. (1902). Šejx Suleyman Efendi’s Čagataj-Osmanisches Wörterbuch. Budapest: Mit Unterstuitzung der Ungarischen Akademie der Wissenschaften.

Mutallibov, S. (1989). Ali̧ser Navåiy Mukammal Asarlar To'plami Yigirma Tomlik To'rtinçi Tom Xazåyinul-Maåniy Navådiruş-şabåb. Tåşkent: O’zbekistån CCR “Fan” Naşriyåti.

Ölmez, Z. K. (1993). Mahbūbü'l-kulūb. (Innceleme-Metin-Sözlük). Yayınlanmamış doktora tezi, Ankara: Hacettepe Üniversitesi Sosyal Bilimler Enstitüsü.

Özkan, F. (1996). Nevayi eserleri için yazılmış bir lügat. (Der. Beyān-1 Istılāhāt-1 Emtahü’şşưarā Mevlānā Nevāyî). Bilig, Sayı,1, Bahar'96, 198-243.

Prokosch, E. (2009). Tschaghataisch-Deutsches glossar. Graz: Universitat Graz. 
Radloff, W. (1893). Versuch Eines Wörterbuchesder Türk-Dialecte I-IV. Saint Petersburg: Tipografiya İmperatorskoy Akademiy Nauk.

Sarıca, B. (2014). Çağatayca-Farsça manzûm bir lügat nisâb-ı Türkî. Ankara: Grafiker Yayınları.

Şamsiyev, P. ve İbråhimov, S. (1972). Navåiy asarlari luğati. Tåşkent: Ğafur Ğulåm Nåmidagi Adabiyåt va San'at Naşriyåti.

Şeyh Süleyman Efendi-yi Buhârî (1298). Luġat-i Çaġatay ve Türkî-yi Osmânî. İstanbul: Mihran Matbaasi.

Thúry, J. (1903). A 'Behdset-ül-lugat' czimü csagatáj szótár. Budapest: Kiadja a Magyar Tudomanyos Akadémia.

Ünlü, S. (2013). Çağatay Türkçesi sözlügü̈. Konya: Eğitim Yayınları.

Üşenmez, E. (2006). Karahanlı Türkçesi sözlüğü̈. Kütahya: Dumlupınar Üniversitesi Sosyal Bilimler Enstitüsü.

Vámbéry, Á. (1862). Abuska Csagatajtörök Szogyüjtemeny. Budapest: Emich Gusztav M. Akad Nyomdasz Betüivel.

Véliaminof-Zernof, V. V. (1869). Dictionnaire djaghatai-Turc. Saint Petersburg: Academie Imperialedes Sciences.

Xasanov, B. (1993). Navåiy asarlari uçun qisqaça luğat. Tåşkent: O’zbekistån Respublikasi Fanlar Akademiyasining "Fan" Naşriyåti.

Xiyavi, R. (1374). Senglāh̆ Ferheng-i Türkỉ be-Fārisī. Tahran: Neşr-i Merkez.

Yıldırım, T. (2002). Hüseyin Baykara divanı. (Metin-İnceleme-Dizin). Yayınlanmamış doktora tezi, Ankara: Ankara Üniversitesi Sosyal Bilimler Enstitüsü.

Zenker, J. T. (1866). Dictionnaire Turc-Arabe-Persan. Leipzig: Verlag von Wilhelm Engelmann, Libraire-Éditeur. 